Article

\title{
Tandem Lewis Pair Polymerization and Organocatalytic Ring-Opening Polymerization for Synthesizing Block and Brush Copolymers
}

\author{
Xing-Yu Sun, Wei-Min Ren *, Si-Jie Liu, Yin-Bao Jia, Yi-Ming Wang and Xiao-Bing Lu * \\ State Key Laboratory of Fine Chemicals, Dalian University of Technology, 2 Linggong Road, Dalian 116024, China; \\ dut_xysun@163.com (X.-Y.S.); lsj21207108@163.com (S.-J.L.); jybks1982@126.com (Y.-B.J.); \\ chemwym@dlut.edu.cn (Y.-M.W.) \\ * Correspondence: wmren@dlut.edu.cn (W.-M.R.); xblu@dlut.edu.cn (X.-B.L.); Tel.: +86-411-84986257 (W.-M.R.); \\ $+86-411-84986255$ (X.-B.L.)
}

Received: 25 January 2018; Accepted: 18 February 2018; Published: 21 February 2018

\begin{abstract}
Lewis pair polymerization is a powerful method for preparing soluble polymers bearing pendant active vinyl groups by directly polymerizing dissymmetric divinyl polar monomers. Herein, we present a strategy for synthesizing block and brush copolymers via tandem Lewis pair polymerization of methacrylates, "thiol-ene" click reaction and organocatalytic ring-opening polymerization of lactide.
\end{abstract}

Keywords: Lewis pair polymerization; click reaction; organocatalytic ring-opening polymerization; block copolymers; brush copolymers

\section{Introduction}

Since the concept "frustrated Lewis pairs" (FLPs), consisted of sterically encumbered Lewis acid and Lewis base pairs, was first described by Stephan and Erker [1], the application of FLP in activating various inert molecules such as $\mathrm{CO}_{2}$ has received intensive attention in recent years [2-7]. The first attempt of using the alane-based classical or frustrated Lewis pairs for polymerizing various polar monomers appeared in 2010 by Chen's group [8,9]. In these systems, the structure of Lewis base had a drastic effect on the catalytic activity and polymerization behaviors [10-13]. In 2013, Amgoune and co-workers described the application of $\mathrm{Zn}\left(\mathrm{C}_{6} \mathrm{~F}_{5}\right)_{2}$-based Lewis pairs in ring-opening polymerization of lactide and $\varepsilon$-caprolactone, affording well-defined high molecular weight cyclic polyesters or cyclic block copolymers [14]. Independently, Dagorne et al. performed the ring-opening polymerization of $\beta$-butyrolactone, lactide, and trimethylene carbonate mediated by neutral and cationic $\mathrm{N}$-heterocyclic carbene zinc adducts and the $\mathrm{BnOH} / \mathrm{Zn}\left(\mathrm{C}_{6} \mathrm{~F}_{5}\right)_{2}$ binary mixture [15]. Subsequently, our group reported that the frustrated Lewis pairs consisted of N-heterocyclic olefins (NHOs) and $\mathrm{Al}\left(\mathrm{C}_{6} \mathrm{~F}_{5}\right)_{3}$ were highly active in polymerizing various polar monomers such as methyl methacrylate (MMA), ${ }^{n}$ butyl methacrylate (BMA), $N, N$-dimethylacrylamide (DMAA) and $\mathrm{N}, \mathrm{N}$-diphenylacrylamide (DPAA) at ambient temperature, affording high molecular weight polymers with relatively narrow distributions [16]. Notably, these frustrated Lewis pairs were discovered to be very efficient in polymerizing dissymmetric divinyl polar monomers at the methylacrylic $\mathrm{C}=\mathrm{C}$ bond in completely regioselective manner at mild conditions, affording soluble polymers bearing pendant active vinyl groups with high molecular weight and narrow polydispersity $\left(M_{\mathrm{w}} / M_{\mathrm{n}}<1.5\right)$ [17].

Unfortunately, the Lewis pair polymerization could not synthesize block copolymers by stepwise addition of two different monomers. ESI-TOF MS study confirmed that the resultant polymer included NHO as the initiation group bound to one end of a polymer chain and an unexpected six-membered ring lactone chain-end, which was formed from the nucleophilic backbiting of the 
polymeric anion to the carboxyl carbon of the adjacent unit, in companion with the release of the methoxyl group [16]. Recently, Rieger and coworkers presented the catalytic polymerization of diverse Michael-type monomers with high precision by using simple but highly active combinations of phosphorus-containing Lewis bases and organoaluminum compounds [18]. The interacting Lewis pairs afforded the living polymerization of a broad variety of sterically demanding and functionalized monomers with high initiator efficiencies up to $95 \%$.

In the present contribution, we report the synthesis of block and brush copolymers via tandem Lewis pair polymerization and organocatalytic ring-opening polymerization.

\section{Results and Discussion}

\subsection{Synthesis of PMMA-b-PLA.}

In previous paper [11], we have demonstrated that the production of lactone end resulted in complete deactivation in polymer chain propagation for $\mathrm{Al}\left(\mathrm{C}_{6} \mathrm{~F}_{5}\right)_{3} /$ Lewis base mediated polymerization of MMA. The Lewis pair consisting $\mathrm{Al}\left(\mathrm{C}_{6} \mathrm{~F}_{5}\right)_{3}$ and N-heterocyclic carbene (NHC, compound 3) with a $\mathrm{C}=\mathrm{C}$ bond group mediated polymerization of MMA predominately afforded PMMA with NHC bounded to one end of a polymer chain and a six-membered lactone ring appeared at another chain end. The vinyl group in NHC end of the resultant PMMA was transferred to hydroxyl group by the click reaction with $\mathrm{HOCH}_{2} \mathrm{CH}_{2} \mathrm{SH}$. The thiol-ene click reaction was clearly confirmed by ESI-TOF MS analysis, in which the species $(515+100 \mathrm{n})$ were observed (Figure 1). The resultant PMMA-OH in Scheme 1 could be directly used as macroinitiators to initiate ring-opening polymerization of lactide with DBU as catalyst at ambient temperature to produce the PMMA- $b$-PLA diblock copolymers, confirmed by ESI-TOF MS analysis (Supporting information, Figure S1). The gel permeation chromatography (GPC) analysis of the resulting copolymers with different lactide loadings demonstrated the formation of the PMMA-b-PLA diblock copolymers (Figure 2, left). The thermal properties of the resulting block copolymers were determined by differential scanning calorimetry (DSC) (Figure 2, right). Only a single glass-transition peak $\left(T_{\mathrm{g}}\right)$ was observed for the block copolymers. There was a gradual decrease in the $T_{\mathrm{g}}$ with the length of PLA segment from racemic lactide, compared with PMMA. Table S1: $\mathrm{PMMA}_{30}-\mathrm{OH}$ initiatied ring openging of lactide to prepare of PMMA-b-PLA copolymer.

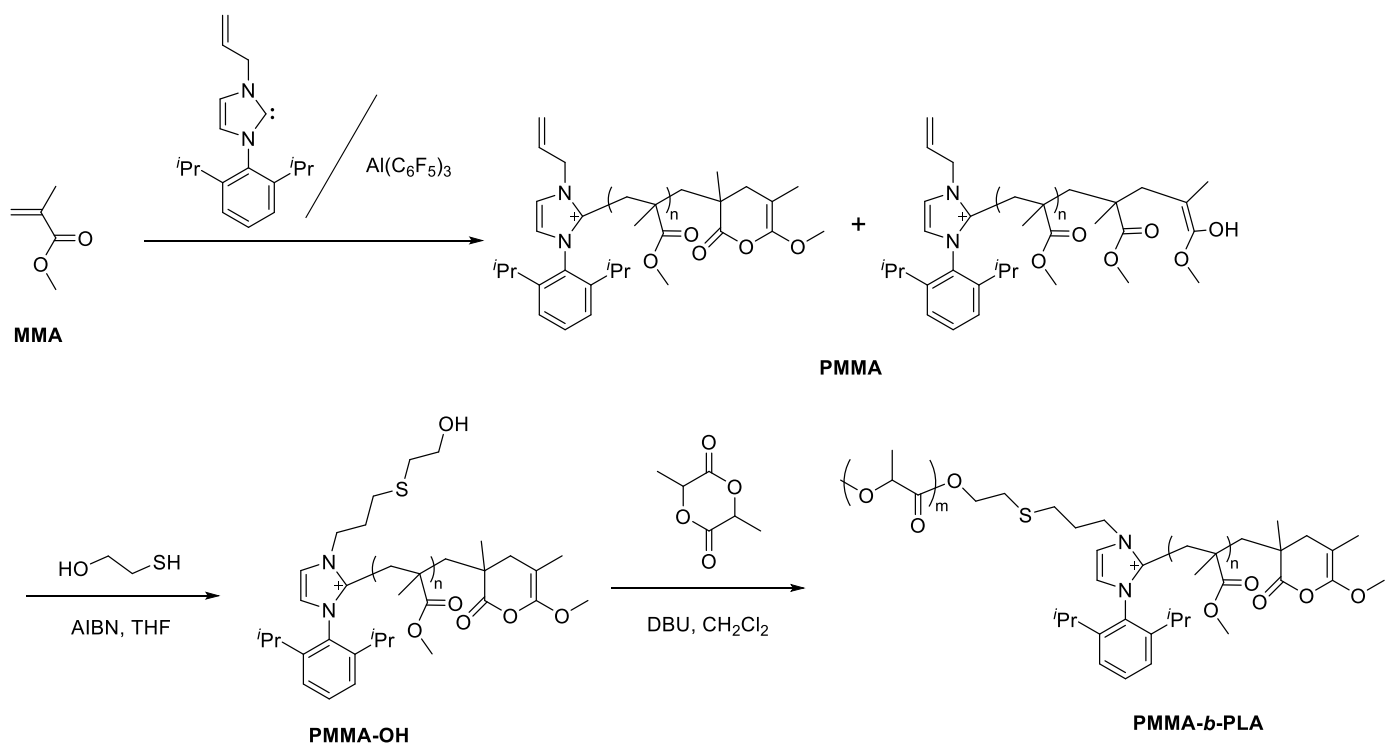

Scheme 1. Synthesis of PMMA- $b$-PLA via tandem Lewis pair polymerization and organocatalytic ring-opening polymerization. 


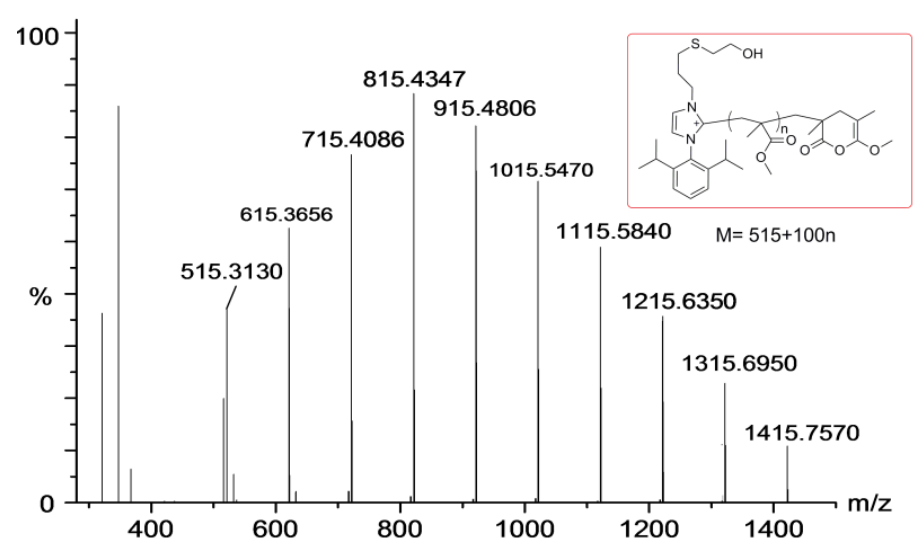

Figure 1. ESI-TOF MS spectrum of PMMA with hydroxyl group at the chain end.
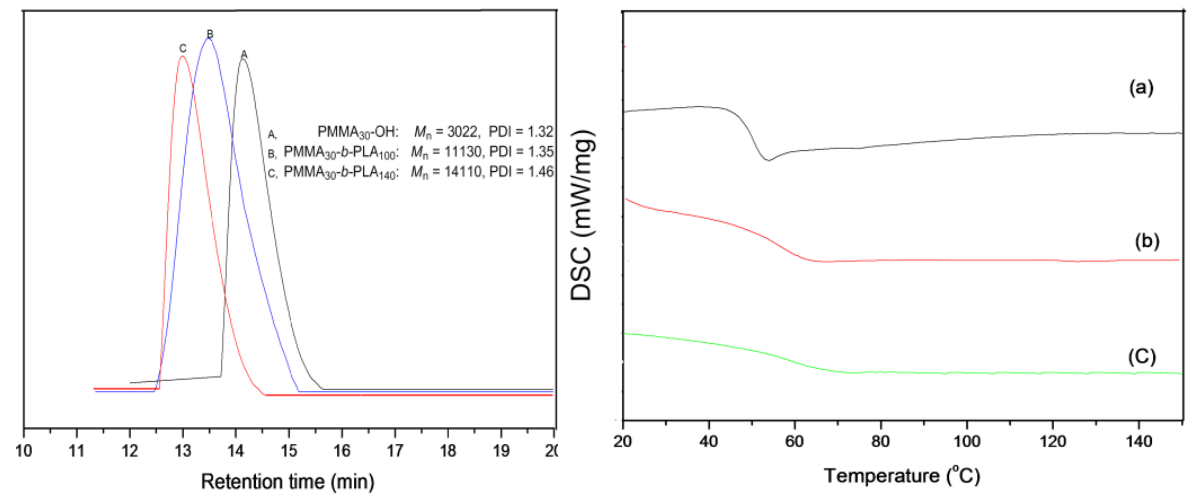

Figure 2. GPC spectra (left) of PMMA- $b$-PLA copolymers, and DSC thermograms (right) of PMMA- $b$-PLA copolymers with a certain amount of PMMA segment $\left(M_{n}(P M M A)=3022\right)$ and different PLA segments: (a) $M_{\mathrm{n}}(\mathrm{PLA})=11088 ;$ (b) $M_{\mathrm{n}}(\mathrm{PLA})=8108 ;(\mathrm{c}) M_{\mathrm{n}}(\mathrm{PLA})=1959$.

\subsection{Synthesis of Brush Copolymers with PMMA Backbone and Grafting PLA Chains}

Lewis pair polymerization is a powerful method for polymerizing dissymmetric divinyl polar monomers in excellent regioselectivity and high reactivity at mild conditions, affording soluble polymers bearing pendant active vinyl groups with high molecular weight and narrow polydispersity [12]. The pendant vinyl groups in polymers are easily functionalized by "thiol-ene" reaction, and the resulting hydroxyl groups can be used as initiators in various ring-opening polymerization of lactones.

In order to obtain well-distributed graft chains in PMMA backbone, the random copolymer $\mathrm{P}$ (MMA-co-VMA) from $\mathrm{Al}\left(\mathrm{C}_{6} \mathrm{~F}_{5}\right)_{3} / \mathrm{NHO}$ mediated copolymerization of MMA and VMA (10:1, molar ratio) was prepared for synthesizing macroinitiators $\mathrm{P}(\mathrm{MMA}-\mathrm{co}-\mathrm{VMA})-\mathrm{OH}$ with multi-hydroxyl sites through the reaction of $\mathrm{P}(\mathrm{MMA}-\mathrm{co}-\mathrm{VMA})$ and excessive $\beta$-mercaptoethanol in the presence of $\alpha, \alpha$-Azobis(isobutyronitrile) (AIBN) at $70{ }^{\circ} \mathrm{C}$ for 24 hours. Since MMA and VMA have the similar reactivities in this polymerization process, the monomers incorporated into the resulting copolymer exhibit a random distribution. After the click reaction of $\mathrm{P}\left(\mathrm{MMA}-\mathrm{co}\right.$-VMA) with $\beta$-mercaptoethanol, ${ }^{1} \mathrm{H}-\mathrm{NMR}$ spectra (Figure 3) showed that the peaks at 7.18, 4.94, and $4.63 \mathrm{ppm}$ belong to the pendant $\mathrm{C}=\mathrm{C}$ bonds disappeared and new peaks at 2.73, and $3.72 \mathrm{ppm}$ (assigned to mercaptoethanol) appeared, indicating all the pendant double bonds have been reacted. The ring-opening polymerization of lactide initiated by $\mathrm{P}$ (MMA-co-VMA)-OH was performed under a [LA]/[-OH] feeding ratio of 10 or 20 , using DBU as catalyst in $\mathrm{CH}_{2} \mathrm{Cl}_{2}$ at $25^{\circ} \mathrm{C}$, affording brush copolymers with PMMA backbone and grafting PLA chains (Scheme 2), ascribed to P(MMA-co-VMA)-g-PLA 10 and P(MMA-co-VMA)-g-PLA 20 , respectively. The GPC traces of the resultant brush copolymers are shown in Figure 4, where it is apparent that an increase in lactide loading 
led to an increase in the copolymer's molecular weight. Of importance, the copolymers display monomodal weight distributions with very narrow PDI values $(<1.30)$, which demonstrates successful chain extension from the side hydroxyl groups of PMMA to afford the predesigned brush copolymers. Figure S4: ${ }^{1} \mathrm{H}-\mathrm{NMR}$ spectrum of NHO, Figure S5: ${ }^{13} \mathrm{C}-\mathrm{NMR}$ spectrum of NHO.

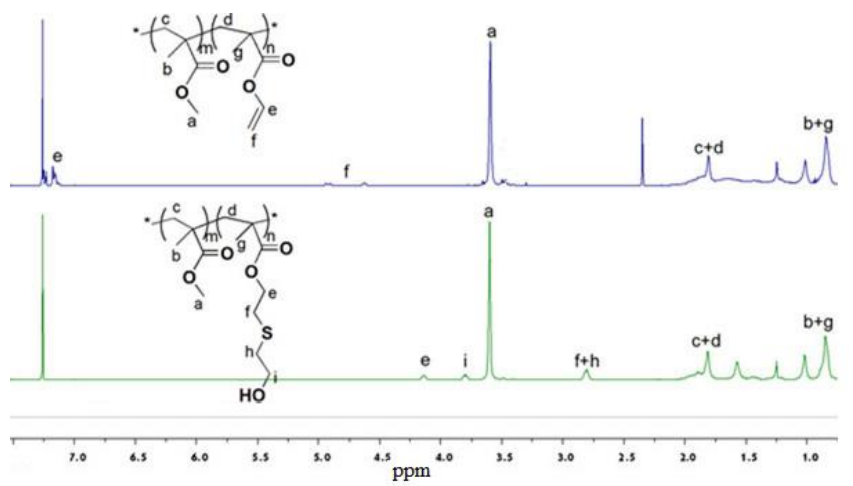

Figure 3. ${ }^{1} \mathrm{H}-\mathrm{NMR}$ spectra of $\mathrm{P}(\mathrm{MMA}-\mathrm{co}-\mathrm{VMA})$ and $\mathrm{P}(\mathrm{MMA}-\mathrm{co}-\mathrm{VMA})-\mathrm{OH}$.

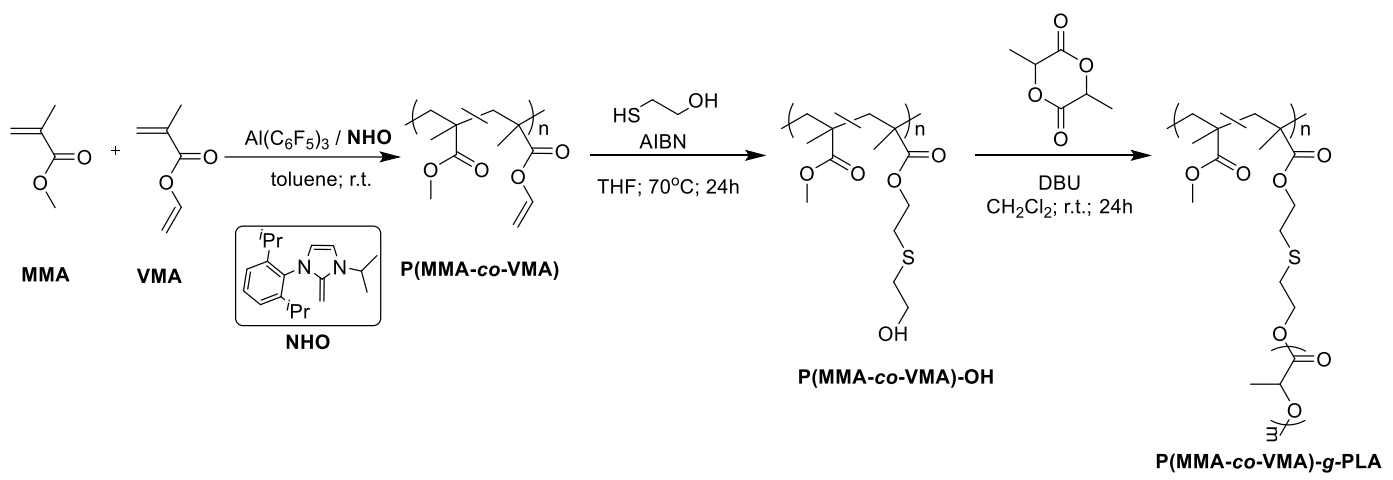

Scheme 2. Synthesis of P(MMA-co-VMA)-g-PLA bush copolymers.

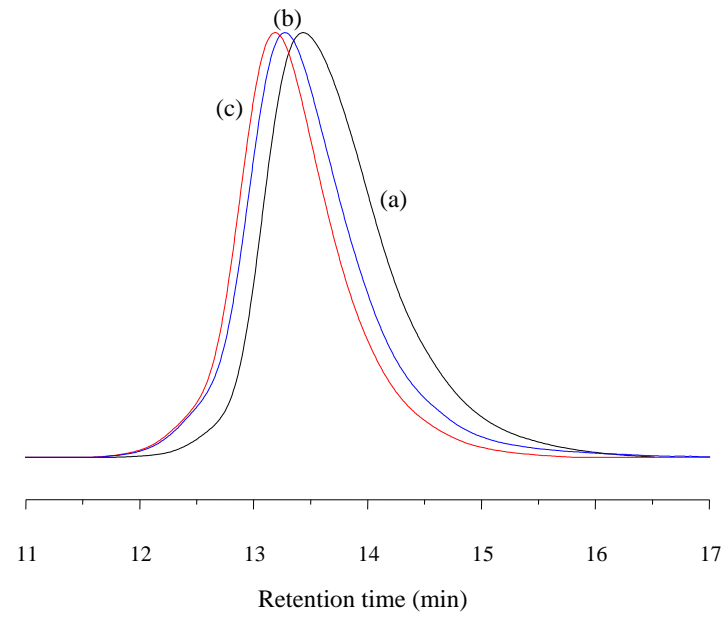

Figure 4. GPC spectrum of (a) P(MMA-co-VMA)-OH $\left(M_{n}=9200\right.$, PDI $\left.=1.26\right)$, (b) P(MMA-coVMA $)-g-P_{10}\left(M_{n}=11900, P D I=1.29\right),(c) P(M M A-c o-V M A)-g-P_{20}\left(M_{n}=13300, P D I=1.28\right)$.

\section{Experimental}

All syntheses and manipulations of air- and moisture-sensitive materials were performed using standard Schlenk techniques under a dry nitrogen atmosphere or an argon-filled glovebox. NMR 
spectra were recorded on a Bruker Avance II $400 \mathrm{M}$ type $\left({ }^{1} \mathrm{H}-\mathrm{NMR}, 400 \mathrm{MHz} ;{ }^{13} \mathrm{C}-\mathrm{NMR}, 100 \mathrm{MHz}\right)$ spectrometer. High resolution mass spectra (HRMS) were recorded on a Q-TOF mass spectrometry (Micromass, Wythenshawe, UK) equipped with a Z-spray ionization source.

Methyl methacrylate (MMA) and vinyl methacrylate (VMA) were degassed and then dried with $\mathrm{CaH}_{2}$ overnight, followed by vacuum distillation under reduced pressures. The purified monomers were stored in brown bottles with $5 \AA$ molecular sieves inside a glovebox freezer at $-30^{\circ} \mathrm{C} . \mathrm{Al}\left(\mathrm{C}_{6} \mathrm{~F}_{5}\right)_{3}$ was prepared by ligand exchange reactions between $\mathrm{B}\left(\mathrm{C}_{6} \mathrm{~F}_{5}\right)_{3}$ and $\mathrm{AlEt}_{3}$. The used N-heterocyclic olefin was prepared according to the literature methods [19].

Polymer average molecular weights $\left(M_{\mathrm{n}}\right)$ and molecular weight distributions $\left(M_{\mathrm{w}} / M_{\mathrm{n}}\right)$ were determined by gel permeation chromatography (GPC) analysis using THF as the eluent with a flow rate of $1.0 \mathrm{~mL} / \mathrm{min}$, on an Agilent 1260 instrument coupled with an Agilent RI detector and equipped with two PL gel $5 \mu \mathrm{m}$ mixed-C columns. The sample concentration was about $0.1 \%$, and the injection volume was $50 \mathrm{uL}$. The curve was calibrated using monodisperse polystyrene standards covering the molecular weight rage from 580 to $460,000 \mathrm{~g} / \mathrm{mol}$. Low-molecular-weight polymers produced by $\mathrm{NHO}$ and $\mathrm{Al}\left(\mathrm{C}_{6} \mathrm{~F}_{5}\right)_{3}$ in toluene was analyzed by electrospray ionization mass spectrometry (ESI-MS) in positive mode, using a Aglient 6224 TOF LC/MS or matrix-assisted laser. Synthesis of asymmetric carbene with a $\mathrm{C}=\mathrm{C}$ bond group was shown in Figure 5.

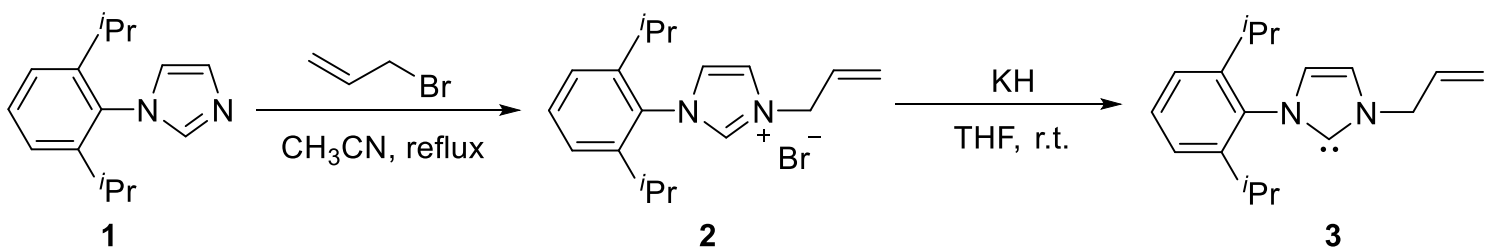

Figure 5. Synthesis of asymmetric carbene with a $\mathrm{C}=\mathrm{C}$ bond group.

\subsection{Synthesis of Compound 2}

A round-bottom flask equipped with a three-way stopcock containing 1-(2,6-bis isopropylphenyl) imidazole of $0.82 \mathrm{~g}$ ( $3.59 \mathrm{mmol})$ dissolved in $20 \mathrm{~mL}$ acetonitrile was purged with dry nitrogen, and 3-bromopropylene $(3.95 \mathrm{mmol})$ was added into the mixture solution. The resulting mixture was refluxed over the night, and the solvent was removed under reduced pressure. The residual was purged with $10 \mathrm{~mL}$ diethyl ether to afford white solid. The solid was purified by column chromatography on silica gel using petrol ether/ethyl acetate (50:1-10:1, gradient elution) to give the compound 2 of $0.8 \mathrm{~g}$ (80\% yield). ${ }^{1} \mathrm{H}-\mathrm{NMR}\left(400 \mathrm{MHz}, \mathrm{DMSO}-d_{6}\right.$, in $\left.p p m\right): \delta=7.46(\mathrm{t}, 1 \mathrm{H}, \mathrm{p}-\mathrm{Ph}), 7.43(\mathrm{t}$, $1 \mathrm{H}, \mathrm{m}-\mathrm{Ph}), 7.26(\mathrm{t}, 1 \mathrm{H}, \mathrm{m}-\mathrm{Ph}), 7.23\left(\mathrm{~d}, 2 \mathrm{H}, \mathrm{CH}_{2}=\mathrm{CH}\right), 6.93\left(\mathrm{t}, 1 \mathrm{H}, \mathrm{CH}=\mathrm{CH}_{2}\right), 2.38\left(\mathrm{~m}, 2 \mathrm{H}, \mathrm{CH}\left(\mathrm{CH}_{3}\right)_{2}\right)$, $2.20\left(\mathrm{~d}, 2 \mathrm{H}, J=4.0 \mathrm{~Hz}, \mathrm{CH}_{2}\right), 1.14\left(\mathrm{~d}, 12 \mathrm{H}, J=8.0 \mathrm{~Hz}, \mathrm{CH}_{3}\right), 1.12\left(\mathrm{~d}, 12 \mathrm{H}, J=8.0 \mathrm{~Hz}, \mathrm{CH}_{3}\right)$.HRMS (ESI, $m / z$ ) calcd. For $\mathrm{C}_{18} \mathrm{H}_{25} \mathrm{~N}_{2}[\mathrm{M}]^{+}=269.2018$, found: 269.2200 .

\subsection{Synthesis of Compound 3}

A Schlenk flask equipped with three-way stopcocks was successively added compound 2 (347 $\mathrm{mg}$, $0.1 \mathrm{mmol})$, THF $(10 \mathrm{~mL})$, and then $\mathrm{KH}(44 \mathrm{mg}, 0.11 \mathrm{mmol})$ in a nitrogen atmosphere. After the mixture solution was stirred 24 hours at ambient temperature and then filtered, the resulting precipitate was washed using THF, and dried under reduced pressure to give compound 3 (70\% yield). ${ }^{1} \mathrm{H}-\mathrm{NMR}$ $\left(400 \mathrm{MHz}, \mathrm{C}_{6} \mathrm{D}_{6}\right.$, in ppm): $\delta=7.35(\mathrm{~m}, 1 \mathrm{H}, \mathrm{p}-\mathrm{Ph}), 7.24(\mathrm{~d}, 2 \mathrm{H}, J=8.0 \mathrm{~Hz}, \mathrm{~m}-\mathrm{Ph}), 7.22(\mathrm{~s}, 1 \mathrm{H}, \mathrm{CH}=\mathrm{CH})$, $6.91\left(\mathrm{~d}, 1 \mathrm{H}, J=4.0 \mathrm{~Hz}, \mathrm{CH}_{2}=\mathrm{CH}\right), 6.85(\mathrm{~s}, 1 \mathrm{H}, \mathrm{CH}=\mathrm{CH}), 6.61\left(\mathrm{~d}, 1 \mathrm{H}, J=4.0 \mathrm{~Hz}, \mathrm{CH}_{2}=\mathrm{CH}\right), 5.20(\mathrm{~m}, 1 \mathrm{H}$, $\left.\mathrm{CH}=\mathrm{CH}_{2}\right), 2.90\left(\mathrm{~m}, 2 \mathrm{H}, \mathrm{CH}\left(\mathrm{CH}_{3}\right)_{2}\right), 2.01\left(\mathrm{~d}, 2 \mathrm{H}, \mathrm{J}=4.0 \mathrm{~Hz}, \mathrm{CH}_{2}\right), 1.28\left(\mathrm{~d}, 12 \mathrm{H}, J=8.0 \mathrm{~Hz}, \mathrm{CH}_{3}\right), 1.17(\mathrm{~d}$, $\left.12 \mathrm{H}, J=8.0 \mathrm{~Hz}, \mathrm{CH}_{3}\right) .{ }^{13} \mathrm{C}-\mathrm{NMR}\left(100 \mathrm{MHz}, \mathrm{C}_{6} \mathrm{D}_{6}\right): \delta=146.04,123.74,31.83,28.50,24.42,23.87,22.92$, $21.29,17.09,14.22,13.29$. Figure S2: ${ }^{1} \mathrm{H}-\mathrm{NMR}$ spectrum of compound 3. Figure S3: ${ }^{13} \mathrm{C}-\mathrm{NMR}$ spectrum of compound 3 . 


\subsection{General Polymerization Procedures}

Lewis pair polymerizations were performed in $20 \mathrm{~mL}$ oven-dried glass reactors inside the glovebox under ambient conditions. A predetermined amount of $\mathrm{Al}\left(\mathrm{C}_{6} \mathrm{~F}_{5}\right)_{3}$ was first dissolved in the monomer MMA/VMA mixture (10/1, molar ratio) and $5 \mathrm{~mL}$ of toluene, and the polymerization was started by rapid addition of a solution of $\mathrm{N}$-heterocyclic olefin in $4 \mathrm{~mL}$ of toluene via a gastight syringe to the mixture solution under vigorous stirring. The molar ratio of Lewis acid to NHO was fixed into $2 / 1$ for all polymerizations. After the desired time, the reaction mixture was immediately quenched by the addition of $2 \mathrm{~mL} \mathrm{5 \%} \mathrm{HCl-acidified} \mathrm{methanol.} \mathrm{The} \mathrm{quenched} \mathrm{mixture} \mathrm{was} \mathrm{precipitated} \mathrm{into} 100 \mathrm{~mL}$ of methanol, stirred for $1 \mathrm{~h}$ and filtered. The resulting polymer was further washed with methanol and dried in a vacuum oven at $50{ }^{\circ} \mathrm{C}$ overnight to a constant weight.

\subsection{Thiol-ene Click Reaction}

A typical procedure was started with the ratio of reagents $\mathrm{C}=\mathrm{C}$ groups (in the copolymer)/ [ $\beta$-mercaptoethanol] $/[\mathrm{AIBN}]=1 / 40 / 0.33$ (molar ratio). Thiol-ene click reaction between P(MMA-co-VMA) (700 mg, $0.623 \mathrm{mmol}$ of $\mathrm{C}=\mathrm{C}$ group $)$ and $\beta$-mercaptoethanol $(1.95 \mathrm{~g}, 25.0 \mathrm{mmol})$ was conducted in a $50 \mathrm{~mL}$ Schlenk flask under nitrogen atmosphere with $10 \mathrm{~mL}$ THF as solvent and AIBN ( $34.0 \mathrm{mg}, 0.210 \mathrm{mmol}$ ) as initiator. The reaction mixture was allowed to stir for $24 \mathrm{~h}$ at $70^{\circ} \mathrm{C}$. Then the solvent and excessive $\beta$-mercaptoethanol were removed by rotary evaporation. The crude product was dissolved into THF and precipitated in methanol. The product was redissolved and reprecipitated for three times and dried by vacuum to a constant weight.

\subsection{Organocatalytic Ring-Opening Polymerization}

In a oven-dried $25 \mathrm{~mL}$ Schlenk flask under nitrogen atmosphere, macroinitiator $\mathrm{P}\left(\mathrm{MMA}_{10} \mathrm{C}^{-\mathrm{co}}\right.$ VMA)-OH (119 mg, $0.100 \mathrm{mmol}$ of hydroxyl group) and catalyst 1,8-diazabicyclo[5.4.0]undec-7-ene (DBU) (150 mg, $0.100 \mathrm{mmol}, 1$ equiv.) were dissolved in $4 \mathrm{~mL}$ toluene, followed the addition of racemic lactide ( 1.00 or $2.00 \mathrm{mmol}, 10$ or 20 equiv.). The reaction mixture was allowed to stir for $24 \mathrm{~h}$ at ambient conditions. After the desired time, the mixture was precipitated into $100 \mathrm{~mL}$ methanol, stirred for $10 \mathrm{~min}$, and then filtered. The crude product was dissolved into THF and precipitated in methanol. The product was redissolved and reprecipitated for three times, and then dried by vacuum to a constant weight.

\section{Conclusions}

We have described the successful synthesis of block and brush copolymers via the Lewis pair mediated polymerization of conjugated polar alkenes, the "thiol-ene" reaction of the vinyl groups in polymers, and DBU-mediated ring-opening polymerization of lactide initiated by the hydroxyl groups on the polymers. The GPC and ${ }^{1} \mathrm{H}-\mathrm{NMR}$ results demonstrated that successful side-chain extension was achieved when $\mathrm{P}(\mathrm{MMA}-\mathrm{co}-\mathrm{VMA})-\mathrm{OH}$ was used to initiated the ring-opening polymerization of lactide. Future efforts will focus on expanding the species of substrates that are building the main or side chain, and on the increasing side chains.

Supplementary Materials: The following are available online at http:/ /www.mdpi.com/1420-3049/23/02/468/s1, Figure S1: ESI-TOF MS spectrum of PMMA-b-PLA copolymer, Figure S2: ${ }^{1} \mathrm{H}-\mathrm{NMR}$ spectrum of compound 3, Figure S3: ${ }^{13} \mathrm{C}$-NMR spectrum of compound 3, Figure S4: ${ }^{1} \mathrm{H}-\mathrm{NMR}$ spectrum of NHO, Figure S5: ${ }^{13} \mathrm{C}-\mathrm{NMR}$ spectrum of NHO, Table S1: $\mathrm{PMMA}_{30}-\mathrm{OH}$ initiatied ring openging of lactide to prepare of PMMA-b-PLA copolymer.

Acknowledgments: This work is supported by the National Natural Science Foundation of China (NSFC, grant numbers 21474011, 51473027), and Program for Chang Jiang Scholars and Innovative Research Team in University (IRT-17R14).

Author Contributions: W.-M.R. and X.-B.L.designed the research; X.-Y.S.,S.-J.L., Y.-B.J. and Y.-M.W. performed the research and analyzed the data; X.-Y.S. and X.-B.L. wrote the paper. All authors read and approved the final manuscript.

Conflicts of Interest: The authors declare no conflict of interest. 


\section{References}

1. Welch, G.C.; San Juan, R.R.; Masuda, J.D.; Stephan, D.W. Reversible, metal-free hydrogen activation. Science 2006, 314, 1124-1126. [CrossRef] [PubMed]

2. Chase, P.A.; Gille, A.L.; Gilbert, T.M.; Stephan, D.W. Frustrated Lewis pairs derived from N-heterocyclic carbenes and Lewis acids. Dalton Trans. 2009, 38, 7179-7188. [CrossRef] [PubMed]

3. Holschumacher, D.; Bannenberg, T.; Hrib, C.G.; Jones, P.G.; Tamm, M. Heterolytic dihydrogen activation by a frustrated carbine-borane Lewis pair. Angew. Chem., Int. Ed. 2008, 47, 7428-7432. [CrossRef] [PubMed]

4. Caputo, C.B.; Zhu, K.; Vukotic, V.N.; Loeb, S.J.; Stephan, D.W. Heterolytic activation of $\mathrm{H}_{2}$ using a mechanically interlocked molecule as a frustrated lewis base. Angew. Chem., Int. Ed. 2013, 52, 960-963. [CrossRef] [PubMed]

5. Mömming, C.M.; Otten, E.; Kehr, G.; Fröhlich, R.; Grimme, S.; Stephan, D.W.; Erker, G. Reversible metal-free carbon dioxide binding by frustrated Lewis pairs. Angew. Chem. Int. Ed. 2009, 48, 6643-6646. [CrossRef] [PubMed]

6. Appelt, C.; Westenberg, H.; Bertini, F.; Ehlers, A.W.; Slootweg, J.C.; Lammertsma, K.; Uhl, W. Geminal phosphorus/aluminum-based frustrated lewis pairs: $\mathrm{C}-\mathrm{H}$ versus $\mathrm{C} \equiv \mathrm{C}$ activation and $\mathrm{CO}_{2}$ fixation. Angew. Chem. Int. Ed. 2011, 50, 3925-3928. [CrossRef] [PubMed]

7. Li, H.; Wen, M.; Lu, G.; Wang, Z.X. Catalytic metal-free intramolecular hydroaminations of non-activated aminoalkenes: A computational exploration. Dalton Trans. 2012, 41, 9091-9100. [CrossRef] [PubMed]

8. Zhang, Y.; Miyake, G.M.; Chen, E.Y. Alane-based classical and frustrated Lewis pairs in polymer synthesis: Rapid polymerization of MMA and naturally renewable methylene butyrolactones into high-molecular-weight polymers. Angew. Chem. Int. Ed. 2010, 49, 10158-10162. [CrossRef] [PubMed]

9. Zhang, Y.; Miyake, G.M.; John, M.G.; Falivene, L.; Caporaso, L.; Cavallo, L.; Chen, E.Y. Lewis pair polymerization by classical and frustrated Lewis pairs: Acid, base and monomer scope and polymerization mechanism. Dalton Trans. 2012, 41, 9119-9134. [CrossRef] [PubMed]

10. Chen, E.Y. Polymerization by classical and frustrated Lewis pairs. Top. Curr. Chem. 2013, 334, $239-260$. [CrossRef] [PubMed]

11. He, J.H.; Zhang, Y.T.; Chen, E.Y.X. Synthesis of Pyridine- and 2-Oxazoline-Functionalized Vinyl Polymers by Alane-Based Frustrated Lewis Pairs. Synlett 2014, 25, 1534-1538. [CrossRef]

12. He, J.H.; Zhang, Y.T.; Falivene, L.; Caporaso, L.; Cavallo, L.; Chen, E.Y.X. Chain Propagation and Termination Mechanisms for Polymerization of Conjugated Polar Alkenes by [Al]-Based Frustrated Lewis Pairs. Macromolecules 2014, 47, 7765-7774. [CrossRef]

13. Xu, T.Q.; Chen, E.Y.X. Probing Site Cooperativity of Frustrated Phosphine/Borane Lewis Pairs by a Polymerization Study. J. Am. Chem. Soc. 2014, 136, 1774-1777. [CrossRef] [PubMed]

14. Piedra-Arroni, E.; Ladaviere, C.; Amgoune, A.; Bourissou, D. Ring-Opening Polymerization with $\mathrm{Zn}\left(\mathrm{C}_{6} \mathrm{~F}_{5}\right)_{2}$-Based Lewis Pairs: Original and Efficient Approach to Cyclic Polyesters. J. Am. Chem. Soc. 2013, 135, 13306-13309. [CrossRef] [PubMed]

15. Schnee, G.; Fliedel, C.; Avilés, T.; Dagorne, S. Neutral and Cationic N-Heterocyclic Carbene Zinc Adducts and the $\mathrm{BnOH} / \mathrm{Zn}\left(\mathrm{C}_{6} \mathrm{~F}_{5}\right)_{2}$ Binary Mixture-Characterization and Use in the Ring-Opening Polymerization of $\beta$-Butyrolactone, Lactide, and Trimethylene Carbonate. Eur. J. Inorg. Chem. 2013, 3699-3709. [CrossRef]

16. Jia, Y.B.; Wang, Y.B.; Ren, W.M.; Xu, T.Q.; Wang, J.; Lu, X.B. Mechanistic Aspects of Initiation and Deactivation in N-Heterocyclic Olefin Mediated Polymerization of Acrylates with Alane as Activator. Macromolecules 2014, 47, 1966-1972. [CrossRef]

17. Jia, Y.B.; Ren, W.M.; Liu, S.J.; Xu, T.Q.; Wang, Y.B.; Lu, X.B. Controlled Divinyl Monomer Polymerization Mediated by Lewis Pairs: A Powerful Synthetic Strategy for Functional Polymers. Acs. Macro. Lett. 2014, 3, 896-899. [CrossRef]

18. Knaus, M.G.M.; Giuman, M.M.; Pothig, A.; Rieger, B. End of Frustration: Catalytic Precision Polymerization with Highly Interacting Lewis Pairs. J. Am. Chem. Soc. 2016, 138, 7776-7781. [CrossRef] [PubMed]

19. Wang, Y.B.; Wang, Y.M.; Zhang, W.Z.; Lu, X.B. Fast $\mathrm{CO}_{2}$ Sequestration, Activation, and Catalytic Transformation Using N-Heterocyclic Olefins. J. Am. Chem. Soc. 2013, 135, 11996-12003. [CrossRef] [PubMed]

Sample Availability: Samples of the compounds in this article are available from the authors. 